\title{
Is E-learning Really the Future or a Risk?
}

\author{
By Charles A. Shoniregun and Sarah-Jane Gray
}

Can e-learning investment decisions be justifiable with the rate in which technology evolves?

Throughout history technological advances in communication have had a dramatic impact on society, for example, the printing press, the telephone, radio, film, television, and more recently the Internet. In education these advances have facilitated the progression from one-to-one tuition to mass education. Early in the last century the use of textbooks permitted national schooling. Film was first used in an educational context by the military during World War II to ensure consistent training around the world. In the UK, the use of television in training was pioneered with the founding of the Open University. But in spite of the success of such ventures, educational television did not replace class learning. Its role remained that of the provider of information rather than of the instructor.

In today's rapidly changing electronic world (e-world) the key to maintaining the appropriate impetus and momentum in organisations and academic environments is knowledge. Therefore, continuous, convenient and economical access to training and qualification assumes the highest priority for the ambitious individual or organisation. This requirement is met by electronic learning (e-learning). E-learning is one of the fastest growing areas of the high technology sector, however the actual uptake of e-learning in the workplace and academic environment has been a lot slower than originally predicted. This paper provides a framework on how an organisation or academic institution should make a rational decision regarding the implementation of e-learning. 
E-learning is the delivery of teaching material electronically with the added value of maintaining standards and quality across the board without the limitation of a specific location. It involves the use of multimedia and is interactive. Multimedia includes more than one form of media such as text graphics, animation, audio, video and video conferencing. Interactivity (interactive learning) is a term that means a computer is used in the delivery of learning material in the context of education and training. In an interactive learning environment, a person can navigate through it, select relevant information, respond to questions using input devices such as a keyboard, mouse, touch screen, or voice command system, complete tasks, communicate with others, and receive assessment feedback.

\section{E-learning and traditional learning}

It is not expected that e-learning will replace traditional forms. According to E. Masie in 'The real truth about e-learning's future," in a few years "there will not be a division between e-learning and traditional learning, as learning will naturally evolve to utilise technological progress to improve learning efficiency" [1]. Most academic institutions and organizations are incorporating blended learning and not just e-learning. This is the use of more than one strategy or delivery system for learning. As learners, we naturally learn through a variety of methods; we talk to colleagues outside of the classroom, read a book, discuss with peers, take an online class etc. E-learning has the power to enormously enrich the learning experience through the use of interactivity and multiple media, both of which are shown by education theory to greatly enhance learning effectiveness. As shown in Figure 1, the retention rate is 80 percent through learning by doing as compared to 10 percent by learning through reading.

Figure 1: The Modes of Learning

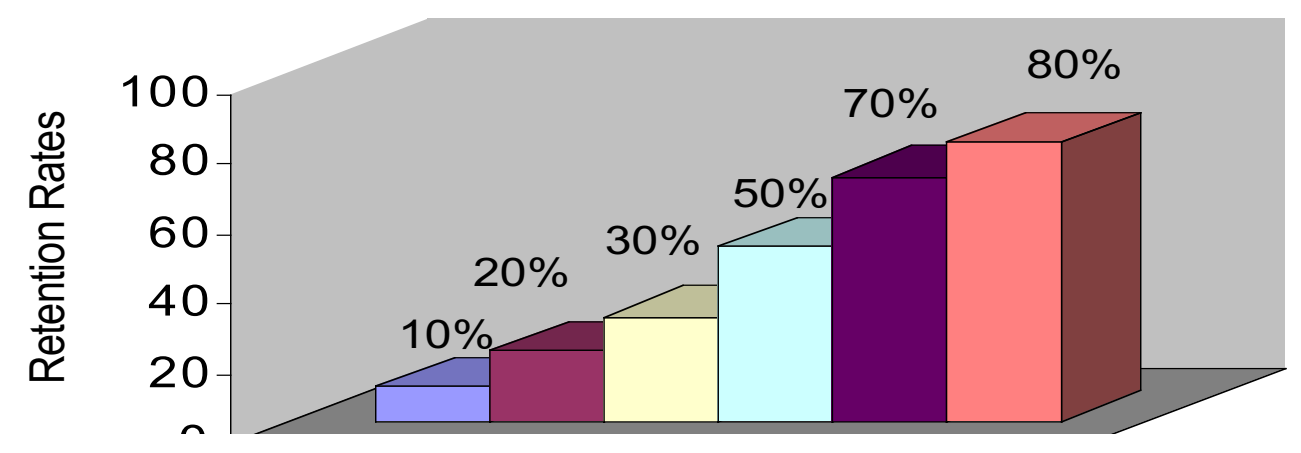


Many training professionals promote a mixture of different styles. "Blended learning" is the new buzzword, explains Jan Hagen, head of the solutions group at the online learning company, Wide Learning [3]. That means using whatever method is most suitable to your company. Sam Woodley, marketing manager from the same company, also states that elearning is not the be-all and end-all of financial training but the great thing about e-learning is that you can train everybody to the same standards before they enter the classroom so the classroom training becomes much more effective. In support of blended learning, e-learning guru Dr. D.S. Preston [4] suggests that the need to sit with other students and with academic mentors is equally vital to learning. Those who deny this may just, through some torpor that is a reversal of the perceived transformation of robot to man, have forgotten what it is to be human and many technological issues remain far from resolved. The greater conceptual difficulties lie in the area of learning itself.

\section{Impact of e-learning sourcing decision}

The impact of e-learning sourcing decisions has led to a combination of self-paced learning such as a Web-based course and the support of an instructor either in the form of face-to-face, email or discussion groups to develop specific skills. The actual costs and benefits of e-learning depend on how e-learning materials are sourced. "What factors are used to justify the e-learning investment decision for organisation or academic institution packages?" Generically, there are three options:

- Purchasing off-the-shelf programs In terms of cost, buying off-theshelf materials is probably the least costly option and the predominant provision of e-learning. There are a considerable number of off-theshelf programs available on the market with many companies offering a trial period before buying. The majority of packages are aimed at developing IT skills, for example the Microsoft certification. Although training for skills such as IT may be generic, organisations of all sizes still have their individual training needs and the content of an off-theshelf program may not be appropriate nor offer the required level of support. It may also be difficult to assess the quality of a program prior to commitment to purchase and so as has often happened, an elearning program could prove to be boring and irrelevant with a high drop out rate. 
- Materials produced by an outside developer. If an e-learning program is not delivering the required training then it may be more cost effective, particularly where large numbers are concerned, to purchase a bespoke course. A bespoke course can focus precisely on those topics relevant to the organisation and be used many times without the cost of licence fees. Rosenberg [5] suggests three reasons why outsourcing may be the most suitable strategy:

a. Although most organisations are involved with learning and training, it is not their principal line of business. As technology is developing rapidly, it may be costly to maintain state-of-the-art e-learning capacity over a long period. By outsourcing, the organisation therefore avoids the risks associated with emerging technologies.

b. A related issue is that of competency. Whilst most organisations will have an IT department, it will be more effective to allocate resources to supporting the organisation's business. External providers will have the necessary expertise for developing the program faster and they will also be aware of recent developments.

c. Finally, there is capacity to consider. As the demand for training fluctuates, outsourcing allows the organisation to expand or reduce training without affecting its own training department.

However, it is necessary to have a thorough understanding of what the organisation and/or the academic institution needs and also to look for a vendor with a stable financial base.

- Developing materials in-house. Of the three options, developing materials in-house seems "to be the way forward". More and more programs will be developed in-house as it can be argued that not only does this keep down costs but it also allows the organisation and/or the academic institution to have full control over the product including copyright. This will enhanced the existing skills so that future development will become easier and the organisation and/or the academic institution can carry out its own maintenance. 


\section{Measuring the return on investment to e-learning}

There are many choices facing an organisation when considering an elearning program. In addition to choice of whether to embark upon such a program at all, there are many e-learning options, each with varying capabilities. Measuring the costs and benefits provides the financial basis for such a decision. I showed that e-learning typically involves a large initial expenditure, followed by relatively low marginal costs thereafter. Hence, the decision to undertake an e-learning program is best viewed as an investment decision. The organisation can calculate the average return on investment (ROI) in e-learning using the following equation:

$$
R O I=\underline{\text { net benefits } \left.\underline{y}_{1}+\text { net benefits } \underline{y}_{2}+\text { net benefits } y_{n}\right) / n} \times 100
$$

Initial investment

Here, net benefit is the benefits less subsequent additional costs. The average net benefit is calculated by adding net benefit for each year and dividing by $\mathrm{n}$, which is the expected life of the investment. This is then divided by the initial cost of the investment and multiplied by 100 to give the result as a percentage. One basic principle of investment analysis is that only incremental costs and benefits are relevant to the calculation of ROI. Only costs associated with the project should be included and not costs that the organisation would otherwise incur. All costs whether direct, such as the cost of software, and indirect costs, such as time spent, should be categorised. A second basic principle, which is often ignored in practice, is that ROIs are only meaningful when compared to an alternative. For instance, the organisation could simultaneously calculate the ROI on the traditional learning method that will be displaced.

\section{Estimation of the elements of the ROI equation.}

The expected life of the investment $(n)$, as technology rarely covers its cost in the first year and rapid development calls for an upgrade about every two to three years, it is common to use the average benefits derived over a three-year period. Although a three-year period gives a more accurate calculation, it is worth noting that it is preferable to break even earlier. Given the rapid change in technology in this area a more suitable solution mav herome availahle shortlv after the initial investment 
Therefore, the initial investment will include the cost associated with the infrastructure, such as a new server and hardware. If computers need to be upgraded due to the e-learning program requirements then this cost should be included. If, however, it had already been planned to upgrade hardware then this cost should not be included, following the incremental cost principle. The reality is more likely to be somewhere in between. For example, bringing forward a planned upgrade to coincide with the elearning program, in which case the cost should be discounted and only the present value of the timing change included.

There will also be the initial cost of assessing the various options involved in an e-learning program. Again it should be the additional cost incurred as most large organisations will have a training department who would normally carry out such research. If additional human resources are required to administer the program then these costs should be included for each year. If the program is outsourced then there is the initial cost of software and any subsequent costs incurred to update the material to fully utilise the benefits of e-learning. If the program proves to be successful and more people subscribe, then there will be the cost of additional licences.

\section{Measuring indirect benefits}

Measuring the indirect benefits of e-learning is notoriously difficult and rarely carried out in practice, as most academic institutions and companies have neither the time nor expertise to carry it out. Other indirect benefits, which are difficult to measure, include the effect on students and staff performance, which may be either positive or negative. Often employees view training as part of their employment package, however if the motivation for adopting an e-learning program is cost reduction as opposed to enhanced performance then this may cause dissatisfaction among employees resulting in a negative result. How the staff views e-learning will vary from one organisation to another but it is likely that there are trends within industries. For example, in a high technology industry such as new media, where the organisational culture is based upon innovation, one would expect staff would be enthusiastic about the opportunity to train using cutting-edge technology whereas in more traditional industries such as the public sector staff may see the opportunity to train off-site as a perk. The age distribution in the organisation is also likely to have an impact on attitude towards elearnino with an older dictrihution more likelv to nrefer a more 
traditional approach. The skill level is another factor, with a highly skilled workforce being more familiar with the technological and self study aspects of e-learning and so more likely to benefit from the advantages of e-learning.

Furthermore, the indirect benefits are difficult to measure. Their importance should be considered carefully as human capital is often an organisation's most costly factor of production. The training program will not only affect current staff but potential staff as the type of training package offered will affect a potential new recruit's decision to join an organisation.

While there has not yet been extensive independent research in ROI of elearning, there are some recent studies of the extent of the uptake of Elearning. A major study in the Chartered Institute of Personnel and Development's annual survey (2002) found that out of 502 respondents (training managers from UK organisations with more than 25 employees) only a third had incorporated any form of e-learning into their training. Out of those using e-learning, only 6 percent $(2$ percent of those surveyed) use it "a lot of the time" while just under 70 percent use it "a little" [6].

Measuring the costs and benefits of e-learning is difficult and in particular there is a lot of room for subjectivity in valuing the intangible costs and benefits. Without a thorough breakdown of measures, ROI can be used to give a misleading indication.

However, the most effective tool for making an investment decision of elearning is to calculate the ROI. This would involves measuring all the cost and benefits but in practice, ROI is rarely calculated as it is considered too difficult. "Can e-learning investment decision be justifiable with the rate in which technology evolves?" Indeed, investment decisions of e-learning will continue to be a matter of debate.

\section{Discussion}

The dominant technology in most discussions of e-learning is the Internet. It has advantages and disadvantages compared to other platforms such as CD-ROM. As a result, the preferred platform differs from one application to another. According to Dennis Quilter, chief executive of a training supplier, the AdVal Group, "CD-ROM is mainly used now to deliver video or for material with heavy animations"[5]. The advantages of the Internet moctly relate to its real time nature These include the 
ability to continuously update and refresh materials, and its ability to provide direct communication with other people. However, in its current form, the Internet has significant limitations due to connections. These include bandwidth, connectivity problems, and spatial inflexibility as a result of the requirement for a phone line (although this may eventually be overcome by wireless technology).

It is widely believed that e-learning will bring an industrial revolution to training and education. IDC (2001), the market research company, forecast last year that the global corporate e-learning market will be worth $\$ 23$ billion in 2003 although this may take a year or two longer following the downturn in the market due to the terrorist events of September 11, 2001. Sheila McGovern, an IDC analyst, forecasts the market in Europe will grow by 46 percent in 2002 and 57 percent by the end of 2003 [7]. At present e-learning is only a small part of the overall global training market. Gartner, the IT analysis group, forecasts the market to rise to over $\$ 33$ billion by 2005 , which would make up almost one third of overall global training market.

The pure cost savings of e-learning are compelling for managers and academia, compared to traditional training courses. Savings arise from less time off work, lower travel costs, smaller hotel bills and potentially more effective learning. IBM has reported saving more than $\$ 80$ million in travel and housing expenses by adopting on-line learning across its worldwide operations.

However, other benefits of e-learning should be taken into account. Claire Schooley, an analyst with Giga Information Group, says it (saving money) cannot be the only reason or Web-based training will fail ... the critical point is to have training that accomplishes objectives and makes employees/students more productive; the cost savings then become secondary [8]. One perspective on this is given by Dr. Preston from the University of East London (School of Computing and Technology) in his paper, "Virtual Value: The British University in E-Crisis" [4]. He states that rather than sit at the back of some stuffy lecture room with poor acoustics where the student attempts to decipher what is being presented, the multimedia system provides high quality sound and vision. He further emphasizes that time can be spent constructively during lunch at work, three hours in the evening at home, or even on a long train journey via mobile phone and laptop. Such a university student thus has no travel costs to a geographically fixed University and does not need to compete with other students for books or a chair in the library. In addition, given that the cvetem is a 74 -hour one the nioht oxwl or vacation student is not 
discriminated against. E-learning courses have the advantages of being flexible, constantly evaluated and can evolve with user needs. The courses can be delivered in short tutorials so that learning can be carried out during working hours.

Forrester interviewed training managers and knowledge officers at 40 Global companies and discovered that all but one already have online initiatives. Of those companies, 67 percent identified cost saving as the main reason for adopting e-learning programs [9]. Whalen and Wright found that while e-learning has higher development costs, these are offset by lower delivery costs [10]. Also, the reduction in course delivery time (course compression) was from 12 hours of traditional instruction to 2.5 hours of e-learning. It has the potential to deliver courses to a larger number of students as well. The amount of multimedia content was also a significant factor in terms of cost savings. The study showed average savings per student ranging from $\$ 702$ to $\$ 1,103$, depending on the level of multimedia.

Indeed, learning is becoming more user friendly day by day and the need to carry out needs assessment to improve performance, achieve goals of the organisation, determine what potential obstacles need to be removed, and the e-learning readiness score are crucial to the future of e-learning in our society. Forrester found e-learning to be unpopular with employees with dropout rates as high as 80 percent. The cause was poor quality material mainly comprised of static HTML pages, which were produced cheaply. This type of static reading is not effective. On-screen reading retention is 30 percent lower than reading with printed materials [9]. This is not the enhanced training that e-learning represents. Managers with a nearsighted attitude seek to cut costs with this type of alternative, cheaper training rather than using the enhanced training or e-learning.

\section{Conclusion}

Indeed, when making a decision to invest in e-learning it is likely an organisation or academic institution will opt for a blended learning approach. The most effective tool for making an investment decision in elearning is to calculate the return on investment(ROI). But before calculating the return on investment in e-learning, the organisation or academic institution has two important strategic choices to make, which affect the profile of cost and benefit. First, the organisation or academic institution almost invariably mixes e-learning and traditional training; thus usino wxhat has come to he knowan as "hlended learnino" Thouoh the 
main driver of blended learning has been concern about cost, both theory and available evidence suggest that blended learning will be more effective than e-learning alone. But the expected costs and benefits in its particular context to make a rational investment decision for E-learning are yet to be met.

Furthermore, the needs assessment of e-learning is different to that of a traditional classroom program as it involves a greater scope of parties. Information technology and human resources departments that have previously been unrelated must work together. But many questions remain unanswered. "Can technology revolutionalise traditional learning by classification and Taxonomy?" "'What are the possible internal and external factors that need to be taken into consideration during the elearning development within an organisation or academic institution?" "'How is e-learning going to be assessed?" Well, is e-learning really the future or a risk? Blended learning will definitely become popular within the next few years.

Charles Adetokunbo Shoniregun has taught in many universities and colleges in the UK. He is currently a lecturer in Computing and Business Information Systems at the School of Computing and Technology (University of East London) and a guest speaker to many universities in the $U K$ and abroad on issues relating to his research and consultancy area: Internet security, risks assessment of technology enable information, electronic and mobile commerce (emC), and risk assessment of telecommunication infrastructure, and applied information systems. He is author of many refereed papers.

Sarah-Jane Gray, is a publishing manager at the London Business School $(L B S)$. She graduated from the University of Liverpool and the University of Greenwich. She has taught in many colleges in the UK. Her research and consultancy areas are Web development and publishing.

\section{References}

[1] E. Masie, 'The real truth about e-learning's future", IT Training, July 2001. 
http://www.train-net.co.uk/news/full_news.cfm?ID=2994 (Assess date July $162002)$

[2] M. T. H.Chi, M. Bassok, M. Lewis, P. Reimann, and P. Glaser, "Selfexplanations: How students study and use examples in learning to solve problems," Cognitive Science, Vol. 13, pp 145-182, 1989.

[3] J. Hagen and D. Quilter, "Understanding E-learning: Moving Inside the Virtual Classroom". edited by J. Lamb, Financial Times, Spring 2002.

[4] Dr. D. S. Preston, Weltzugäne: Virtualität Realität, "The British University in E-Crisis: Virtual Value," Sozialität, Schneider Verlag Hohengehren, Germany, 2002.

[5] Rosenberg M J, E-Learning -- strategies for delivering knowledge in the digital

age, McGraw-Hill, 2001

[6] CIPD, 2002, "E-Learning. Where are we now?" Chartered Institute of Personnel and Development

[7] S. McGovern, "Finding the Right Mix" edited by Mark Vernon, Financial Times, Spring 2002.

[8] C. Scholely, "Understanding E-learning: A Better Way to Learn" edited by A. Fisher, Financial Times, Spring 2002.

[9] J. P. Forrester et al, The Forrester Report, "Online Training Needs A New Course: Methodology for cost-benefit analysis of Web-based tele learning: Case Study of the Bell Online Institute", August 2000.

[10] T. Whalen and D. Wright, "Methodology for cost-benefit analysis of web-based tele learning: Case Study of the Bell Online Institute", The American Journal of Distance Education, Vol. 13, No. 1, 1999. 
